\title{
Comparative analysis of bacterial community composition in bulk tank raw milk by culture-dependent and culture-independent methods using the viability dye propidium monoazide
}

\author{
Mareike Weber, ${ }^{*}$ Janina Geißert, $†$ Myriam Kruse, ${ }^{*}$ and André Lipski*1 \\ ${ }^{*}$ Rheinische Friedrich-Wilhelms-Universität Bonn, Institut für Ernährungs- und Lebensmittelwissenschaften, \\ Abteilung Lebensmittelmikrobiologie und -hygiene, Meckenheimer Allee 168, 53115 Bonn, Germany \\ †Universität Tübingen, Institut für Medizinische Mikrobiologie und Hygiene, Elfriede-Aulhorn Str. 6, 72076 Tübingen, Germany
}

\begin{abstract}
Microbial diversity of 3 raw milk samples after $72 \mathrm{~h}$ of storage at $4^{\circ} \mathrm{C}$ in a bulk tank was analyzed by culturedependent and -independent methods. The culturedependent approach was based on the isolation of bacteria on complex and selective media, chemotaxonomic differentiation of isolates, and subsequent identification by $16 \mathrm{~S}$ rRNA gene sequencing. The culture-independent approach included the treatment of raw milk with the dye propidium monoazide before direct DNA extraction by mechanic and enzymatic cell lysis approaches, and cloning and sequencing of the $16 \mathrm{~S}$ rRNA genes. The selective detection of viable bacteria improved the comparability between bacterial compositions of raw milk based on culture-dependent and -independent methods, which was the major objective of this study. Several bacterial species of the phyla Actinobacteria, Bacteroidetes, Firmicutes, and Proteobacteria were detected by the culture-dependent method, whereas mainly bacteria of the phylum Proteobacteria as well as low proportions of the phyla Bacteroidetes and Actinobacteria were detected by the culture-independent method. This led to the conclusion that the phylum Firmicutes was strongly discriminated by the cultureindependent approach. Generally, species richness detected by the culture-dependent method was higher than that detected by the culture-independent method for all samples. However, few taxa could be detected solely by the direct DNA-based method. In conclusion, the combination of culture-dependent and -independent methods led to the detection of the highest bacterial diversity for the raw milk samples analyzed. It was shown that DNA extraction from raw milk as the essential step in culture-independent methods causes the discrimination of taxa by incomplete cell lysis. Treatment of raw milk with the viability dye propidium monoazide
\end{abstract}

Received May 8, 2014

Accepted August 1, 2014.

${ }^{1}$ Corresponding author: lipski@uni-bonn.de was optimized for the application in raw milk without former removal of milk ingredients and proved to be a suitable tool to ensure comparability of bacterial diversity depicted by both methods.

Key words: propidium monoazide, bacterial community, raw milk

\section{INTRODUCTION}

Bacterial community structure in bulk tank raw milk is an important factor influencing quality and safety of the product milk itself as well as of processed dairy products, as it reflects hygienic conditions during milking and storage of raw milk in the bulk tank. Contamination of raw milk during the milking process depends on udder and teat microbiota, which is influenced by the stable environment. Primarily gram-positive bacteria, such as staphylococci, corynebacteria, bacilli, and the genus Kocuria, but also some gram-negative species of the family Enterobacteriaceae can contaminate raw milk from this source (Vacheyrou et al., 2011; VerdierMetz et al., 2012). Other sources of contamination are the milking machine and the bulk tank itself, where biofilms can establish if cleaning and disinfection procedures are insufficient (Hayes et al., 2001; Teh et al., 2011). Especially psychrotolerant species, such as the gram-negative genera Acinetobacter and mainly Pseudomonas, may contribute to product spoilage, as they are able to proliferate at low storage temperatures and become the dominating genera in cold-stored raw milk (Raats et al., 2011). Moreover, some species were shown to produce heat-resistant lipases and proteases (Hantsis-Zacharov and Halpern, 2007), which may cause product spoilage even after pasteurization of the milk. The level of contamination is influenced by hygienic conditions and milking practice as well as cleaning and disinfection success of the milking equipment and bulk tank (Verdier-Metz et al., 2009; Pantoja et al., 2011).

Analyses of raw milk microbiota are based on culturedependent methods (Hantsis-Zacharov and Halpern, 2007; Vacheyrou et al., 2011), direct molecular methods 
(Lafarge et al., 2004; Verdier-Metz et al., 2009), or a combination of both (Rasolofo et al., 2010; Fricker et al., 2011; Verdier-Metz et al., 2012). Culture-dependent methods are more time consuming than cultureindependent methods and incubation conditions and media influence the detected community composition. Moreover, bacteria that entered the "viable but nonculturable" state described by Oliver (2005) cannot be detected by culturing methods. In contrast, culture-independent methods using PCR amplification of $16 \mathrm{~S}$ rRNA genes are less time consuming and well established in non-food research areas. They are also of increasing interest in dairy research (Giraffa and Neviani, 2001; Justé et al., 2008). However, direct comparison between species diversity determined by culture-dependent and -independent methods could lead to misinterpretations, as direct DNA-based methods detect also dead cells as well as extracellular DNA, which has been shown to persist in different matrices from a few days up to weeks (Josephson et al., 1993; McKillip et al., 1999). This is especially important for food products, as spoilage and the risk potential of pathogens depend on their viability. This challenge can be overcome by using viable PCR (vPCR), which makes use of one of the dyes ethidium monoazide or propidium monoazide (PMA). These dyes can selectively penetrate cells with impaired membrane integrity, where they intercalate into DNA molecules. Photoactivation by intense light produces covalent bonds between dye and DNA molecules, hindering PCR amplification of DNA molecules carrying this modification (Nogva et al., 2003; Nocker et al., 2006).

Viable PCR using PMA has been applied to few dairy products so far. The use of PMA was described for application in fermented milk (García-Cayuela et al., 2009), cheese (Desfossés-Foucault et al., 2012), and pasteurized (Soejima et al., 2012) and UHT milk (Cattani et al., 2013) for selective detection of certain lactic acid bacteria, spoiling organisms, or pathogens. Moreover, in most studies, the milk matrix was removed by proteolysis and washing steps before PMA treatment, and no information exists about interactions of PMA with milk components potentially hindering successful live-dead discrimination. Intense washing steps preceding PMA treatment and DNA extraction could result in loss of bacteria, though, and would reduce the detectable bacterial diversity by DNA-based methods.

To our knowledge, vPCR using PMA has not yet been applied to analyze bacterial community structure in raw milk. Therefore, the aim of this study was the adaptation of PMA-treatment and DNA-extraction methods for use in the raw milk matrix. We focused on the development of raw milk PMA treatment without preceding purification from certain milk compounds and the application of as gently as possible washing steps before DNA extraction. Moreover, the depicted bacterial community structure gained by application of vPCR combined with cloning was compared with the community structure presented by traditional culturedependent techniques to assess the coverage of bacterial sequences obtained by direct DNA extraction from raw milk.

\section{MATERIALS AND METHODS}

\section{Raw Milk Sampling}

Three raw milk samples were taken from the bulk tank (Kryos 6BII; WestfaliaSurge Japy SAS, Saint Apollinaire, France) of a research farm of the University of Bonn (Königswinter, Germany) after $72 \mathrm{~h}$ of cold storage at $4^{\circ} \mathrm{C}$. Here, raw milk of about 60 cows of the breed German Holstein is collected twice daily using modern milking equipment and cold stored in the bulk tank for $72 \mathrm{~h}$ before pick up by the purchaser. Until further processing in the laboratory on the same day, milk samples were transported under refrigerated conditions. The samples, further referred to as milk sample 1 (M1) and milk sample 3 (M3), were taken in April of 2 consecutive years (2012 and 2013), whereas milk sample 2 (M2) was taken in August 2012. Milk sample 1 was analyzed by culturing methods, M2 was analyzed using the culture-independent method, and M3 was analyzed using both methods in a parallel approach.

\section{Enumeration and Isolation of Bacteria}

Raw milk was serially diluted in Ringer's solution and $100-\mu \mathrm{L}$ aliquots of each dilution as well as the undiluted milk sample were spread in duplicate on the following media (all by Merck KGaA, Darmstadt, Germany): Trypticase soy agar (TSA) for total bacterial count (TBC), violet red bile agar (VRBA) for coliform count $(\mathbf{C C})$, skim milk plate count agar, and de Man, Rogosa, and Sharpe (MRS) agar for the detection of lactic acid bacteria. Plates were incubated for $48 \mathrm{~h}$ at $30^{\circ} \mathrm{C}$ or at $37^{\circ} \mathrm{C}$ (VRBA). The MRS agar was incubated anaerobically at $30^{\circ} \mathrm{C}$. From each medium, a variety of morphologically different colonies was randomly selected for isolation and purified on TSA for subsequent identification.

\section{Differentiation and Identification of Isolates}

Isolates were characterized according to their colony and cell morphology, visualized by light microscopy (BH2; Olympus Europa SE \& Co. KG, Hamburg, 
Germany). Further differentiation was achieved via Gram staining (Gerhardt et al., 1981), KOH lysis test and detection of L-alanine aminopeptidase by use of Bactident L-alanine aminopeptidase test strips (Merck $\mathrm{KGaA}$ ). Fatty acid profiles of the isolates were determined after growth on TSA for $48 \mathrm{~h}$ at $30^{\circ} \mathrm{C}$. Fatty acid methyl ester preparation followed the methods described by Sasser (1990). Fatty acid methyl ester extracts were analyzed by GC-MS with a gas chromatograph (model 7890A; Agilent Technologies Germany GmbH, Waldbronn, Germany) equipped with a $5 \%$ phenyl methyl silicone capillary column and a mass spectrometer (model 5975C; Agilent Technologies Germany GmbH) as described previously (Lipski and Altendorf, 1997). Fatty acid methyl esters were identified by their retention time and by their mass spectra (ChemStation; Agilent Technologies Germany GmbH). Double-bondpositions of monounsaturated fatty acids were located by dimethyl disulfide derivatization (Sigma-Aldrich Chemie GmbH, Hamburg, Germany) as described by Nichols et al. (1986). Isolates were differentiated into groups according to their FA profiles.

The DNA extraction, PCR amplification, and sequencing of $16 \mathrm{~S}$ rRNA genes were performed as described previously (Wiertz et al., 2013). The isolates were identified by searching their $16 \mathrm{~S}$ rRNA gene sequence against the databases EzTaxon-e server (Kim et al., 2012) and GenBank using the Basic local alignment search tool (BLAST; Altschul et al., 1990) at the National Center for Biotechnology Information (NCBI) website (http://blast.ncbi.nlm.nih.gov/Blast.cgi).

\section{PMA Treatment of Raw Milk}

A preliminary test was conducted with raw milk inoculated with the isolate Pantoea agglomerans M1_I4, followed by either heat inactivation $\left(100^{\circ} \mathrm{C}\right.$ for $\left.10 \mathrm{~min}\right)$ or not, and subsequent PMA treatment [stock solution: $20 \mathrm{~m} M$ PMA (Biotium Inc., Hayward, CA) in $20 \%$ dimethyl sulfoxide (AppliChem GmbH, Darmstadt, Germany)] at a final concentration of $100 \mu M$. A heatinactivated and a viable sample without PMA treatment were used as control. Success of heat inactivation was tested by cultivation on TSA. In the main trial, 2 aliquots of $10 \mathrm{~mL}$ of raw milk were treated with $50 \mu \mathrm{L}$ of PMA stock solution, resulting in a final concentration of $100 \mu M$. Two aliquots of $10 \mathrm{~mL}$ of untreated raw milk and 2 aliquots of $10 \mathrm{~mL}$ of inoculated raw milk (M2 inoculated with Pantoea agglomerans M1_I4 and Microbacterium ginsengiterrae M1_I6, and M3 inoculated with Escherichia coli DSM 498 and Staphylococcus aureus DSM 1104) served as controls for successful live-dead discrimination and DNA extraction, respectively.
Propidium monoazide-treated samples were incubated in the dark for 5 min with periodic mixing. For PMA induction, 1-mL aliquots were filled into 2-mL reaction tubes and placed horizontally onto aluminum foil covered with ice from both sides, laying in a glass vessel, which was shaken on a platform shaker at $150 \mathrm{rpm}$. Light exposure was conducted with a 400-W halogen lamp (R7s, 9,000 lumen; Osram GmbH, Augsburg, Germany) at a $20-\mathrm{cm}$ distance to the tubes for 5 min.

\section{DNA Extraction from Raw Milk and PCR Amplification}

Raw milk was centrifuged at 13,000 $\times g$ for $20 \mathrm{~min}$ at $4^{\circ} \mathrm{C}$. The pellet was washed with $0.9 \% \mathrm{NaCl}$ and after repeated centrifugation under identical conditions, cell lysis and DNA extraction were carried out using 2 different approaches of the Qiagen DNeasy Blood and Tissue Kit (Qiagen GmbH, Hilden, Germany) as modifications of the manufacturer's protocol. In an enzymatic approach, the cell pellet was suspended in $600 \mu \mathrm{L}$ of lysis buffer $[20 \mathrm{~m} M$ Tris $\mathrm{HCl}(\mathrm{pH} 8.2), 2 \mathrm{mM}$ EDTA, and $1.2 \%$ Triton X-100] containing lysozyme $(5 \mathrm{mg} / \mathrm{mL}$ ), and $30 \mu \mathrm{L}$ of mutanolysin (stock solution: $\geq 4,000 \mathrm{U}$ in $0.1 \mathrm{M}$ potassium phosphate buffer, $\mathrm{pH}$ 6.2; all chemicals by Sigma-Aldrich Biochemie GmbH). After $1.5 \mathrm{~h}$ of incubation at $37^{\circ} \mathrm{C}, 400 \mu \mathrm{L}$ of buffer $\mathrm{AL}$ and $50 \mu \mathrm{L}$ of Proteinase $\mathrm{K}$ (both from Qiagen $\mathrm{GmbH}$ ) were added and an overnight incubation step at $55^{\circ} \mathrm{C}$ with gentle shaking followed. In a mechanical lysis approach, the cell pellet was suspended in $1 \mathrm{~mL}$ of $0.9 \%$ $\mathrm{NaCl}$; transferred to a $2-\mathrm{mL}$ reaction tube, which was filled with sterile 2-mm glass beads (Merck KGaA); and mixed for $10 \mathrm{~min}$. After transfer of this mix to a $15-\mathrm{mL}$ reaction tube, $360 \mu \mathrm{L}$ of buffer ATL (Qiagen $\mathrm{GmbH}$ ) and $50 \mu \mathrm{L}$ of proteinase $\mathrm{K}$ were added and an overnight incubation step at $55^{\circ} \mathrm{C}$ with gentle shaking followed. The next day, $400 \mu \mathrm{L}$ of buffer AL was added, which was followed by an incubation step for $30 \mathrm{~min}$ at $70^{\circ} \mathrm{C}$. Four hundred microliters of ethanol (Merck KGaA, Darmstadt, Germany) was added to all mixes, solutions were transferred into DNeasy mini columns, and further DNA extraction was carried out according to the manufacturer's instructions. The $16 \mathrm{~S}$ rRNA genes were amplified using primer pair GM3F and GM4R (Muyzer et al., 1995) and PCR products were purified using the QIAquick PCR purification kit (Qiagen $\mathrm{GmbH})$.

\section{Construction of 16S rRNA Gene Clone Libraries}

Purified PCR-products of both lysis approaches were cloned using the pGEM-T vector system and 
transformed into competent E. coli JM 109 cells as specified by the manufacturer (Promega Corp., Madison, WI). From each clone library, inserts of randomly selected clones were amplified using primer pair M13F and M13R (Messing, 1983). The PCR products were confirmed by electrophoresis, purified, and sequenced as described above. All sequences were checked using the Pintail program (Ashelford et al., 2005) and chimeric sequences were excluded from further analyses. Approved sequences were compared with the public databases described above.

\section{Statistical Analysis and Construction of Phylogenetic Trees}

To assess the completeness of total sequence diversity determined by the number of sequenced clone inserts, Rarefaction analysis was conducted using the program Analytic Rarefaction (http://www.uga.edu/ strata/ software) and coverage was calculated according to Good (1953), with assignment of sequences to the same operational taxonomic unit (OTU) at $\geq 99 \%$ sequence similarity (Singleton et al., 2001). Shannon-Index and equitability were calculated for each sample (Shannon and Weaver, 1969).

For each OTU and method of investigation, one representative sequence was used for phylogenetic tree construction using the MEGA 5.1 program (Tamura et al., 2011). Operational taxonomic unit sequences and sequences of their closest relative type strains taken from the databases used for species identification were aligned using the ClustalW program (Thompson et al., 1994). A neighbor-joining phylogenetic tree (Saitou and Nei, 1987) was constructed and assessed by bootstrap analysis with 1,000 resamplings. Representative sequences obtained in this study were deposited in the European Nucleotide Archive under the accession numbers HG934344 to HG934384.

\section{RESULTS}

\section{Bacterial Counts and Grouping of Isolates}

Total bacterial counts were $3.5 \times 10^{3} \mathrm{cfu} / \mathrm{mL}$ for $\mathrm{M} 1$ and $2.9 \times 10^{3} \mathrm{cfu} / \mathrm{mL}$ for M3, whereas TBC for M2 was about $2 \log$ levels higher $\left(1.9 \times 10^{5} \mathrm{cfu} / \mathrm{mL}\right)$. Samples M1 and M3 also contained similar concentrations of coliform bacteria with $3.0 \times 10^{2} \mathrm{cfu} / \mathrm{mL}$ for $\mathrm{M} 1$ and $8.4 \times 10^{2} \mathrm{cfu} / \mathrm{mL}$ for M3. The CC for M2 was higher than for M1 and M3 $\left(1.7 \times 10^{5} \mathrm{cfu} / \mathrm{mL}\right)$. Isolates were divided into 22 groups/subgroups according to their morphological features, Gram-staining, and FA profiles. Profile data of these groups and subgroups are given in the Appendix (Tables A1 to A4).

\section{Bacterial Community Structure as Determined by the Culture-Dependent Method}

At least one representative isolate from each group or subgroup was identified by $16 \mathrm{~S}$ rRNA gene sequencing. Species identification as well as number of identified isolates per species are presented in Table 1. Isolates were assigned to a species if sequence similarity between isolate and the type strain of a species was $\geq 98 \%$. Due to the differentiation according to FA profiles, percentages of each phylum in raw milk samples M1 and M3 were calculated on the basis of total number of isolates, as shown in Table 2. Sample M1 contained $39 \%$ of species belonging to each of the phyla Actinobacteria and Firmicutes, with most in the genera Corynebacterium and Staphylococcus. Sixteen percent of species belonged to the phylum Proteobacteria, with Acinetobacter as the predominant genus and 1 isolate was identified as Flavobacterium spp. affiliated with the phylum Bacteroidetes. Predominant in sample M3 was the phylum Proteobacteria, to which $57 \%$ of the isolates were assigned. The most abundant genera were Escherichia, Acinetobacter, and Pseudomonas. The phylum Firmicutes was represented by $24 \%$ of the isolates, most of them belonging to different species of the genus Staphylococcus. The phyla Actinobacteria, with a high species richness of the genus Corynebacterium, and Bacteroidetes were represented by 13 and $5 \%$ of the isolates, respectively.

\section{Optimization of PMA Treatment for Raw Milk}

As shown in Figure 1, after PMA treatment $(100 \mu M$ final concentration) of inoculated and heat-inactivated raw milk, a significant reduction in PCR product band intensity occurred compared with the untreated sample containing heat-inactivated bacteria. The PMA treatment at a final concentration of $100 \mu M$ did not restrain DNA extraction of living bacteria in raw milk and subsequent PCR amplification, as band intensities of the untreated sample inoculated with living cells and the PMA treated sample were similar (Figure 1). A lower PMA concentration of $50 \mu M$ was not sufficient to prevent PCR amplification of DNA from heat-inactivated cells (data not shown).

\section{Bacterial Community Structure as Determined by the Culture-Independent Method}

Polymerase chain reaction product bands could be detected for the PMA-treated enzymatic and mechanic cell lysis approaches of sample M2 (Figure 2). As the band intensity of the mechanical approach was weak, a second PCR with the same primers was conducted 
Table 1. Species and genera detected in bulk tank raw milk samples as determined by culture-dependent methods and clone libraries ${ }^{1}$

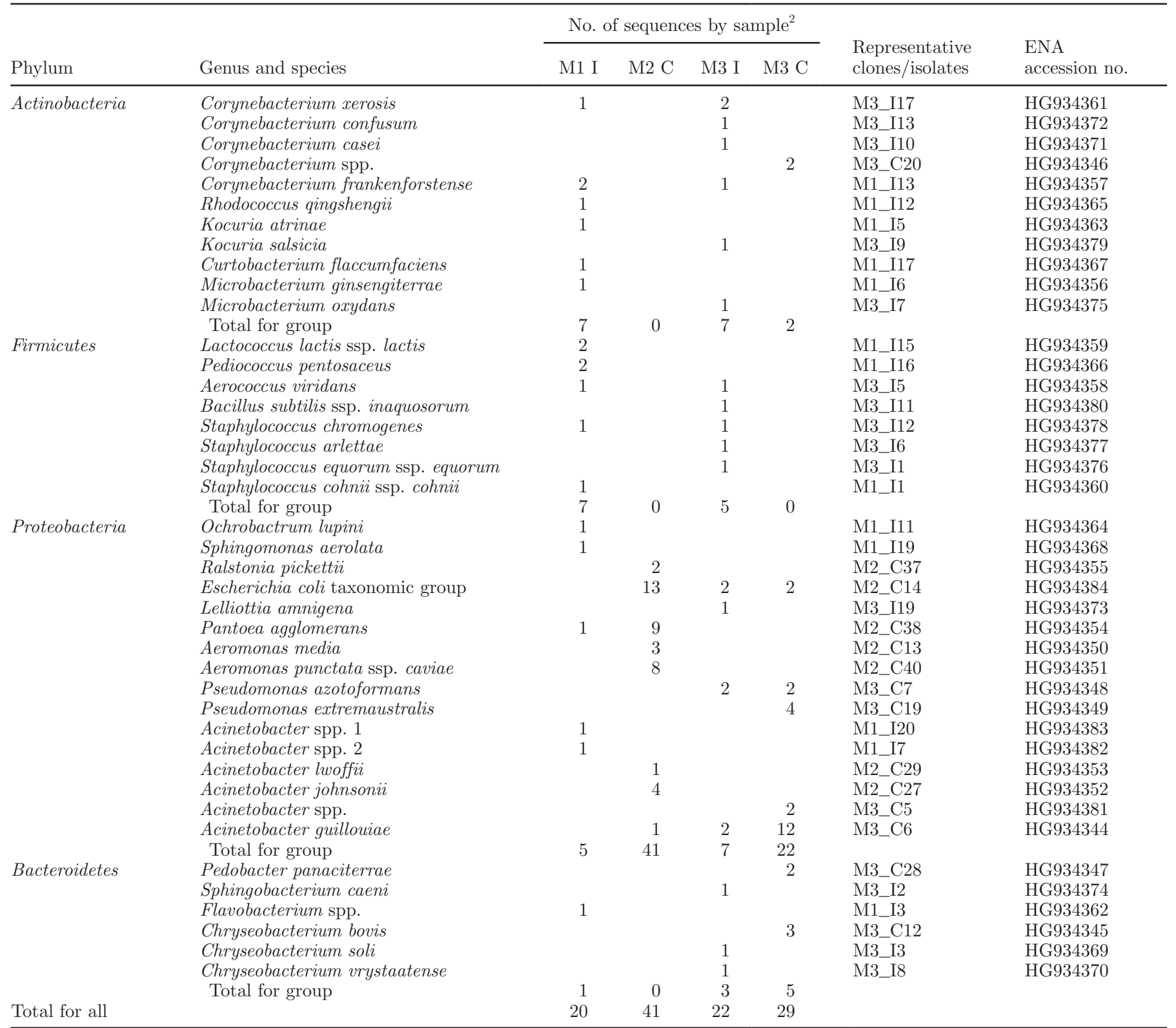

${ }^{1}$ Genus/species affiliation was determined as sequence similarity to type strains obtained by the BLAST database (http://blast.ncbi.nlm.nih. gov/Blast.cgi; Altschul et al., 1990) and EzTaxon-e server (Kim et al., 2012). One representative sequence for each species was deposited in the European Nucleotide Archive (ENA; http://www.ebi.ac.uk/ena/) with the given accession numbers.

${ }^{2} \mathrm{I}=$ isolate sequence; $\mathrm{C}=$ clone library sequence.

using the first product as template. This resulted in brighter product band intensity. In the case of this sample, PCR products from PMA-treated milk of both lysis approaches were used to construct clone libraries. In contrast, the enzymatic lysis approach for the PMAtreated sample M3 resulted in a weak PCR product band intensity, which gave only a low yield of clones. To increase the amount of PCR product, the DNA extract was further concentrated and a second PCR was performed, resulting in brighter product band intensity that gave a higher number of clones. Neither a second PCR of the first product nor further concentration of the DNA extract led to a detectable product from the mechanical cell lysis approach of sample M3. Therefore, no clone library was constructed for this approach. As can be seen in Tables 1 and 2, all 41 sequenced inserts of sample M2 belonged to species of the phylum Proteobacteria, with Escherichia, Aeromonas, and Pantoea as predominant genera. On the basis of all 29 sequenced inserts of sample M3, the majority $(76 \%)$ was also as- 
Table 2. Abundance of detected genera related to the 3 tank milk samples and 2 approaches ${ }^{1}$

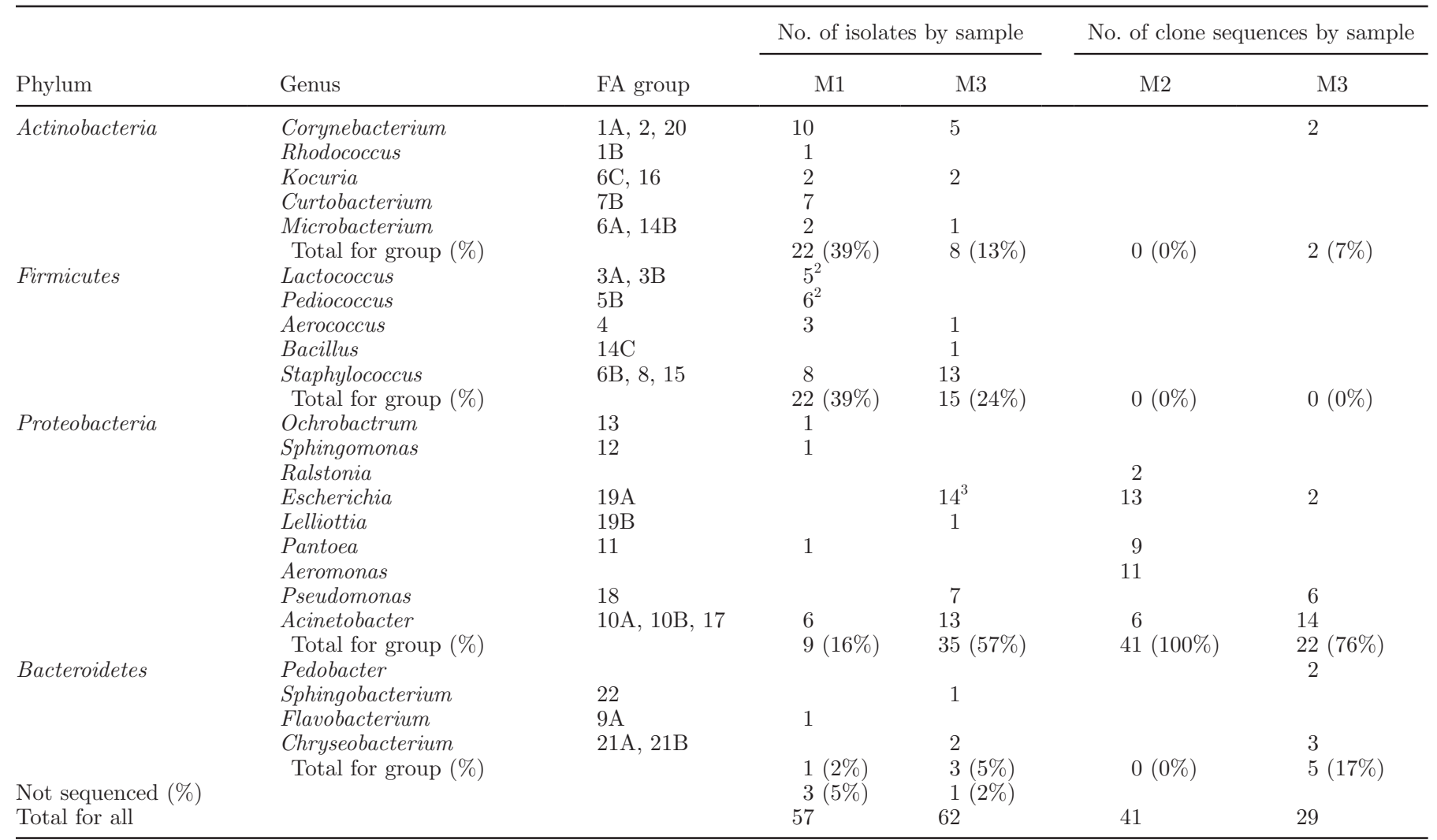

\footnotetext{
${ }^{1}$ Genus affiliation of nonsequenced isolates was determined according to the FA profile groups (see Appendix Tables A1 to A4 for detailed information). Phylum percentages were calculated for each sample and method and are given in parentheses.

${ }^{2}$ Two of the 5 isolates identified as the genus Lactococcus and all 6 isolates identified as the genus Pediococcus were obtained from de Man, Rogosa, and Sharpe (MRS) agar, a selective medium for lactic acid bacteria. Thus, the overall abundance of these genera in relation to total number of isolates might have been overestimated.

${ }^{3}$ Five of the 14 isolates identified as the genus Escherichia were obtained from violet red bile agar, a selective medium for coliform bacteria. Thus, overall abundance of this genus in relation to total number of isolates might have been overestimated.
}

signed to the Proteobacteria, predominated by sequences of the genera Acinetobacter and Pseudomonas, followed by $17 \%$ of the sequences belonging to the phylum Bacteroidetes and 2 sequences $(7 \%)$ affiliated to the genus Corynebacterium of the phylum Actinobacteria.

Coverage for cloned sequences was calculated as $95.1 \%$ for sample M2 and $100 \%$ for sample M3. Rarefaction analysis showed achievement of the plateau phase of the curve after sequencing of 29 clone inserts for sample M3, but a slight increase of the trend line for sample M2. This indicates that bacterial community diversity was almost completely covered (M2) or completely covered (M3; Figure 3).

\section{Overall Bacterial Community Structure as Determined by Culture-Dependent and Culture-Independent Methods}

The phylogenetic tree (Figure 4) represents evolutionary distance between the isolate and clone sequences obtained from all 3 milk samples and their most closely related type strains. Sequence labels illustrate the origin of the sequence (milk samples M1 to M3), the method applied [isolation (I) or cloning (C)], and the total number of similar sequences from the respective approach in parentheses. One representative sequence for each OTU and its European Nucleotide Archive accession number can be found in Table 1. Most sequences showed at least $98 \%$ similarity to known type strains, except for the isolates M1_I3 with only $94 \%$ sequence similarity to type strain Flavobacterium ummariense DS- $12^{\mathrm{T}}$, M1_I7 with $97.1 \%$ sequence similarity to type strain Acinetobacter johnsonii CIP $64.6^{\mathrm{T}}$, M1_I20 with $96.6 \%$ sequence similarity to type strain Acinetobacter junii CIP $64.5^{\mathrm{T}}$, and clone sequence M3_C20 with similarity of $95.9 \%$ to type strain Corynebacterium doosanense CAU $212^{\mathrm{T}}$. These sequences indicate the presence of yet undescribed species.

Whereas the culture-dependent approach resulted in the isolation of bacteria of the phyla Actinobacteria, 


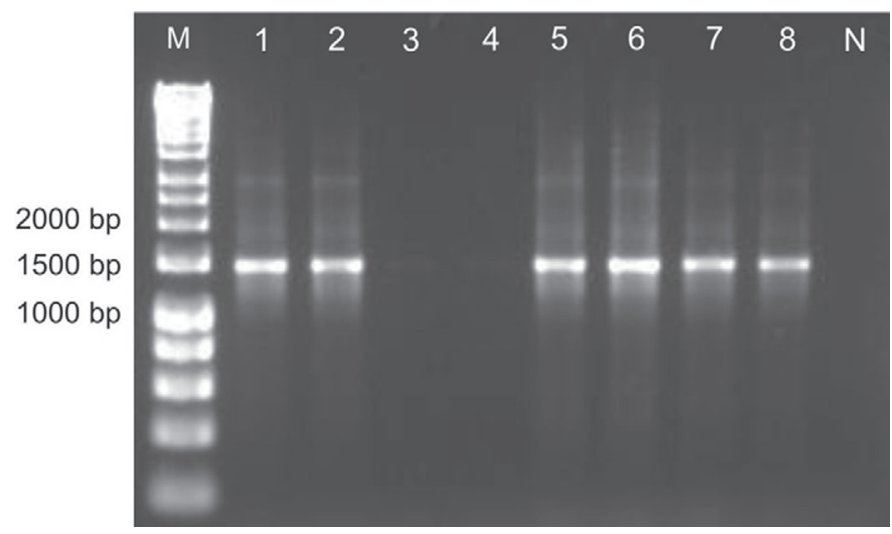

Figure 1. Polymerase chain reaction products on a $1 \%$ agarose gel of the intact or heat-inactivated isolate Pantoea agglomerans M1_I4 in raw milk treated or not treated with propidium monoazide (PMA) at a final concentration of $100 \mu M$ before DNA extraction. Lanes 1 and 2 $=$ raw milk inoculated with intact isolate with PMA; lanes 3 and 4 $=$ inoculated and heat-inactivated raw milk with PMA; lanes 5 and 6 $=$ raw milk inoculated with intact isolate without PMA; lanes 7 and 8 = inoculated and heat-inactivated raw milk without PMA; $\mathrm{N}=$ negative control (PCR reaction without bacterial DNA); $\mathrm{M}=$ marker (Hyper Ladder I; Bioline GmbH, Luckenwalde, Germany).

Firmicutes, Proteobacteria, and Bacteroidetes, with 17 different species from 14 genera in sample M1 and 18 different species from 12 genera in sample M3, the clone libraries for samples M2 and M3 did not depict similar species richness. For M2, 8 species from 5 genera of the phylum Proteobacteria were detected in the clone libraries for both lysis approaches, whereas the clone libraries from the enzymatic lysis approach of M3 resulted in the most sequences being from the phylum Proteobacteria, followed by Bacteroidetes and 2 Actinobacteria sequences with 8 species of 6 genera overall.

Shannon diversity, calculated for the set of isolates obtained from samples M1 and M3, were 2.79 and 2.84, respectively, with equitability values of 0.98 . Shannon indices and equitabilities for samples M2 and M3, analyzed by the culture-independent method, were lower, with values of 1.76 and 1.79 , and 0.85 and 0.86 , respectively. Thus, detected species diversity of the same habitat was higher for the samples M1 and M3 analyzed by the culture-dependent method than for the samples M2 and M3 analyzed by the direct, cultureindependent approach. An equitability value of almost 1 also indicates an even distribution of species within the isolates, whereas lower values for samples M2 and M3 investigated by the culture-independent method indicate higher tendency toward dominance of individual species.

\section{DISCUSSION}

To our knowledge, this is the first study comparing culture-dependent and culture-independent methods for bacterial community analysis of bulk tank raw milk comprising the application of viable PCR with PMA for live-dead discrimination of bacterial cells before DNA extraction. This ensures comparability of the depicted bacterial community structure of both methods.
Raw milk sample 2 (M2)

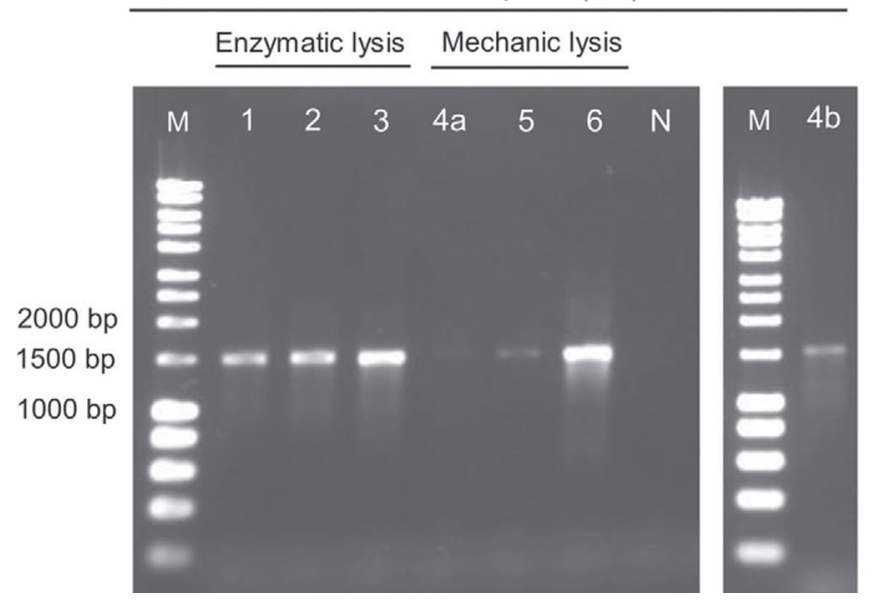

Raw milk sample $3(\mathrm{M} 3)$

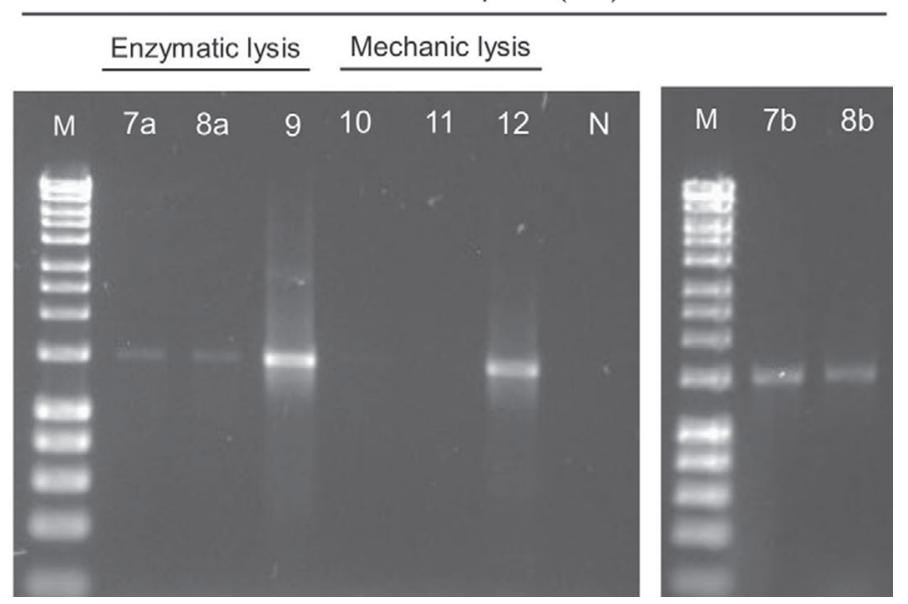

Figure 2. Polymerase chain reaction products on a $1 \%$ agarose gel from raw milk sample 2 (M2; left) and raw milk sample 3 (M3; right) treated with $100 \mu M$ propidium monoazide (PMA) before DNA extraction using enzymatic and mechanic cell lysis approaches. Lanes 1 and 4 a = M2 + PMA; lanes 2 and 5 = M2 without PMA; lane $3=\mathrm{M} 2$ inoculated with isolate Microbacterium ginsengiterrae M1_I6 without PMA; lane $4 \mathrm{~b}=$ reamplification of the PCR product from 4a; lane $6=\mathrm{M} 2$ inoculated with isolate Pantoea agglomerans M1_I4 without PMA; lanes $7 \mathrm{a}$ and $10=\mathrm{M} 3+\mathrm{PMA}$; lane $7 \mathrm{~b}=\mathrm{M} 3+\mathrm{PMA}$ after further concentration of the DNA extract; lanes 8a and $11=\mathrm{M} 3$ without PMA; lane 8b = M3 without PMA after further concentration of the DNA extract; lanes 9 and $12=$ M3 inoculated with a mixture of Escherichia coli DSM 498 and Staphylococcus aureus DSM 1104 without PMA; N = negative control (PCR reaction without DNA); M =marker (Hyper Ladder I; Bioline GmbH, Luckenwalde, Germany). 


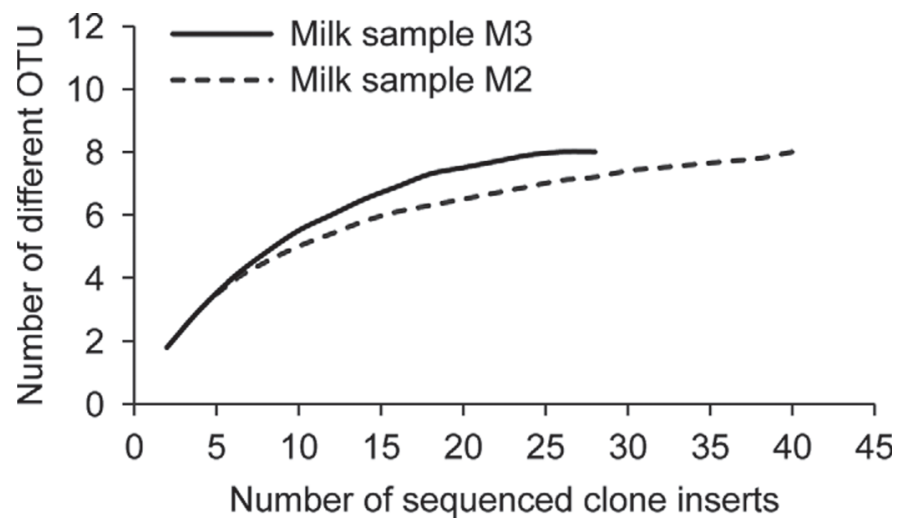

Figure 3. Rarefaction analysis of clone sequences obtained from raw milk sample M2 and raw milk sample M3 conducted with the program Analytic Rarefaction (http://www.uga.edu/ strata/software). $\mathrm{OTU}=$ operational taxonomic units.

Total bacterial counts and CC for milk samples M1 and $\mathrm{M} 3$ reflected very good quality of the raw milk that had been stored in the bulk tank at $4^{\circ} \mathrm{C}$ for $72 \mathrm{~h}$ before sampling. In milk sample M2, after similar storage conditions, TBC and CC were of a higher magnitude, each in the range of $10^{5} \mathrm{cfu} / \mathrm{mL}$, thus reflecting the poor quality of this sample. Short-term increases of bacterial counts caused by rapid proliferation of streptococci or Enterobacteriaceae are a well-known phenomenon for bulk tank milk (Hayes et al., 2001). Similar cell counts from TBC and CC suggested the dominance of Enterobacteriaceae for sample M2. The detection of clone sequences dominated by Enterobacteriaceae sequences support this assumption. In contrast, for samples M1 and M3 the CC were substantially lower than the TBC. This supports the assumption that sample M2 was not representative of bacterial community composition and TBC of the analyzed bulk tank can be considered as a spike (Hayes et al., 2001) for this sample.

Most bacterial genera detected in the milk samples analyzed here have already been reported for raw milk as well as teat skin and farm environment by other authors (Fricker et al., 2011; Vacheyrou et al., 2011; Verdier-Metz et al., 2012). Based on the culturing approach, samples M1 and M3 were dominated by grampositive isolates of the phyla Actinobacteria and Firmicutes, probably originating from teat skin, whereas gram-negative isolates of the phylum Proteobacteria and Bacteroidetes formed the minority in both samples. However, TBC and CC for both samples were similar. In accordance with Rasolofo et al. (2010), on the third day of refrigerated storage of raw milk, species of the genera Staphylococcus, Corynebacterium, and Acinetobacter accounted for high percentages of bacteria isolated from samples M1 and M3. Moreover, the genus Pseudomonas was isolated quite often from sample M3.
Propidium monoazide treatment as well as DNAextraction methods were optimized for raw milk in preliminary experiments. The experiments were conducted with $S$. aureus DSM 1104 and E. coli DSM 498 in nutrient broth and milk (data not shown) and confirmed that PMA photoinduction did not reduce the number of colony-forming units per milliliter of these test strains and, therefore, had no effect on the viability of bacteria. Propidium monoazide treatment at a final concentration of $100 \mu M$ had no effect on DNA extraction from living bacteria. This was in accord with other reports of other authors about PMA-treated samples of living bacteria at a final concentration of $100 \mu M$ (Bae and Wuertz, 2009; Nocker et al., 2009). Nocker et al. (2006) observed occurrence of DNA loss from living E. coli $\mathrm{O} 157: \mathrm{H} 7$ only after increasing the final PMA concentration to $240 \mu \mathrm{M}$, whereas ethidium monoazide was shown to exert cytotoxic effects as well as the ability to penetrate into living cells at lower concentrations (Nocker et al., 2006; Cawthorn and Witthuhn, 2008). Thus, PMA treatment is better suited for reliable and almost complete depiction of mixed bacterial communities of unknown composition (Fittipaldi et al., 2012). Somatic cell eukaryotic DNA as well as milk compounds may be able to reduce effective PMA concentration by chemical adsorption or by shielding of bacterial cells during photoactivation. This effect has been discussed for compounds of environmental samples by other authors (Bae and Wuertz, 2009; Fittipaldi et al., 2012). However, our preliminary experiments with inoculated and heat-inactivated raw milk showed no negative effect of the milk matrix on live-dead discrimination (Figure 1).

Cell lysis and DNA extraction using silica gel columns of the DNeasy Blood and Tissue Kit (Qiagen $\mathrm{GmbH}$ ) followed modified protocols of the manufacturer and literature. As in the present study, Di Pinto et al. (2007) increased amounts of the kit's lysis buffers and of proteinase $\mathrm{K}$ for bacterial cell disruption and DNA extraction from complex food matrices. Milk compounds, such as lipids, whey proteins, and caseins, may function as possible PCR inhibitors (Wilson, 1997) and were successfully removed by centrifugation, washing steps, and proteinase K treatment, as PCR amplification of $16 \mathrm{~S}$ rRNA genes for clone library construction succeeded.

Species diversity in samples M1 and M3 detected by the culture-dependent approach was higher and more evenly distributed than diversity and distribution values for the samples M2 and M3 investigated culture independently. This was demonstrated by calculation of the Shannon index and equitability. Especially the gram-positive phyla Firmicutes and Actinobacteria were underrepresented in the clone libraries (Tables 1 


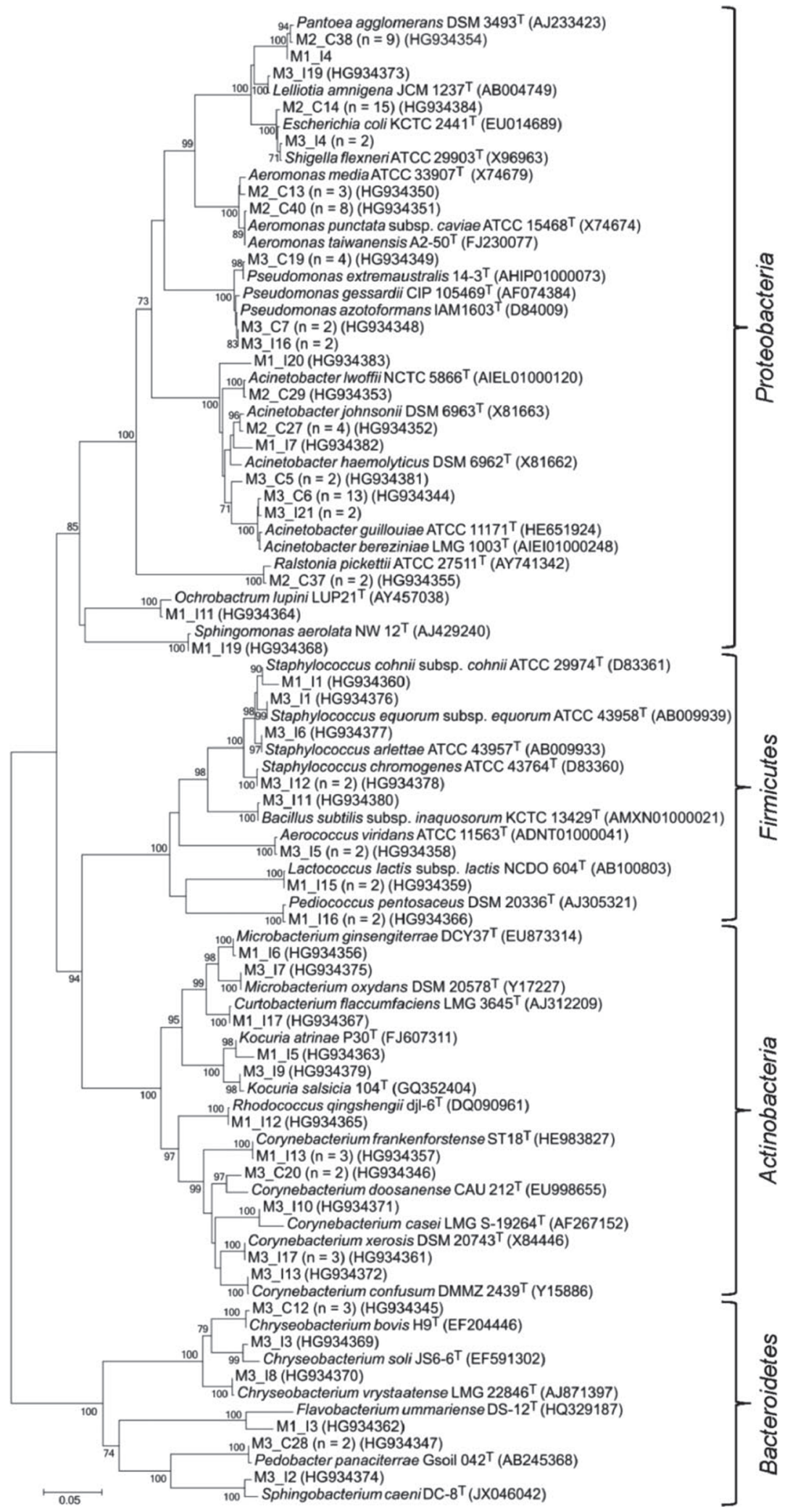

Figure 4. Neighbor-joining phylogenetic tree of isolates (I) and clone sequences (C), constructed the "partial deletion" mode and a cut-off value of $70 \%$. Numbers indicate the strain number of the respective isolate or the number of the clone sequence and numbers in parentheses give the total numbers of sequences with $\geq 99 \%$ similarity gained by the respective approach. Correctness of topology was validated by bootstrap with 1,000 repeats; bootstrap values $\geq 70 \%$ are presented. 
and 2). Detection of species belonging to the phylum Firmicutes in samples M1 and M3 by the culturedependent approach, but not by the direct approach, demonstrated that representatives of this phylum were discriminated by the culture-independent approach used in this study. Because a high number of sequences from gram-negative Proteobacteria were detected within the clone libraries for samples M2 and M3, we concluded that DNA extraction by silica gel columns and PCR amplification were not inhibited by the raw milk matrix. A subsequent experiment proved that the raw milk matrix had an inhibitory effect on enzymatic cell lysis of Staphylococcus chromogenes M3_I12 using species-specific primers but not on cell lysis of the isolate Corynebacterium xerosis M3_I17. In contrast to the Staphylococcus strain, this representative of the Actinobacteria could be clearly detected within the milk matrix (data not shown). Both strains were isolated from sample M3. Other authors also concluded that direct DNA extraction from milk samples may be hampered by sample compounds (Cremonesi et al., 2006; Yeung, 2012), which has crucial influence on the depicted bacterial diversity.

In most other studies investigating raw milk by culture-independent methods, preferential DNA extraction of gram-negative bacteria has not been observed (Rasolofo et al., 2010; Raats et al., 2011; Quigley et al., 2013). Nevertheless, Fricker et al. (2011) detected a higher proportion of gram-negative bacteria within clone libraries compared with culture-dependent methods and none of the cloned sequences was assigned to the genus Staphylococcus. This is in accordance with our study. Although 2 Staphylococcus sequences could also be detected by cloning of $16 \mathrm{~S}$ rRNA genes after DNA extraction directly from raw milk, Delbès et al. (2007) detected higher diversity of the genus Staphylococcus by culturing approaches. For cultivation-independent detection of staphylococci, the enzymatic lysis approach described in our study could possibly be optimized by additional use of lysostaphin, as reported by VerdierMetz et al. (2012), or by a combination of mechanical and enzymatic cell lysis.

In contrast to the cultivation approach, the phylum Actinobacteria was poorly represented in the clone libraries of samples M2 and M3. This may be attributed to the high GC (guanine-cytosine) content of their DNA (Suzuki and Giovannoni, 1996; von Wintzingerode et al., 1997). Preferred amplification of sequences with low GC content probably occurs more frequently in mixtures of different $16 \mathrm{~S}$ rRNA genes.

The mechanical cell lysis approach resulted in a detectable PCR product after a second amplification only for sample M2 with increased TBC, whereas for M3, no detectable product could be achieved at all. This meth- od of cell lysis is probably better suited for raw milk containing large amounts of bacteria because the probability of repeated collisions with glass beads as well as frictional forces between the cells themselves rises with increased cell numbers. All chimeric sequences detected in sample M2 originated from the PCR product of the mechanical lysis approach. The occurrence of these artifacts may be related to the application of a second PCR to the first product using the same primers.

Polymerase chain reaction product yield was quite low for the enzymatic approach as well, but could be increased by concentration of the DNA extract of sample M3. Despite the low DNA concentrations obtained after direct extraction from $10 \mathrm{~mL}$ of raw milk, we refrained from the use of higher raw milk volumes, as we considered saturation of the silica columns by bacterial and bovine DNA. Other studies described successful DNA extraction from raw milk sample volumes of $250 \mu \mathrm{L}$ (Verdier-Metz et al., 2009) or $1 \mathrm{~mL}$ (Delbès et al., 2007; Quigley et al., 2013), so evidence exists that representative DNA extracts may also be obtained from lower amounts of raw milk. Yuan et al. (2012) showed that the extracted amount of DNA is not related to the detected microbial diversity. Even PCR products derived from small amounts of DNA, such as in the present study, are sufficient for an almost complete representation of bacterial diversity in the sample. The rarefaction analysis and calculation of coverage for samples M2 and M3 demonstrated that the diversity within the PCR products was almost completely covered by the sequencing approach. However, the bias introduced by cell lysis, DNA extraction, and PCR amplification could not be assessed by our diversity analyses.

The results of the present study showed that assessment of bacteriological quality of milk samples was possible using the well-established culturing method for determination of TBC and CC. Via grouping of the isolates and subsequent identification of representative individuals for each group, percentages of each phylum were calculated with reference to total number of isolates (Table 2). Thus, estimations could be made for the original culturable bacterial community composition at the time of sampling. Nevertheless, complete coverage of the microbiota by culturing methods is unrealistic, as a preselection of bacteria is performed by choice of media, incubation conditions, and temperatures as well as selection of morphologically significantly different colonies for isolation. Lebaron et al. (1998) described large species variability within similar colony morphotypes from marine environmental samples. Consequently, different species within the same colony morphotype could have been underestimated in the present study. The detection of different species within the same genus by the culture-dependent method and by the culture- 
independent method could be a hint for the correctness of this assumption.

Selective media, such as VRBA for coliform bacteria and MRS agar for lactic acid bacteria, provide particularly good growth conditions for the respective bacteria. By isolation from these media, percentages of corresponding genera in the original milk sample might be overestimated by relation to the total number of isolates. This could be the case for the genera Lactococcus and Pediococcus from sample M1 as well as for the E. coli isolates from sample M3. Two of the 5 Lactococcus isolates and all 6 Pediococcus isolates were obtained from MRS agar, whereas 5 of the 14 Escherichia isolates were obtained from VRBA. Consequently, their percentages in Table 2 might have been overestimated. Another disadvantage of culture-dependent methods is that they are more time consuming than cultureindependent methods. Moreover, they are not able to detect bacteria in the "viable but nonculturable" state (Oliver, 2005). However, isolation techniques are and will be fundamental for the in-depth characterization of exceptional strains, which may represent new species from this source. The microbial diversity of raw milk is still a growing area of research (Wiertz et al., 2013).

In contrast, culture-independent methods, based on detection of DNA should be able to provide a more complete picture of the community of living bacteria in raw milk. Successful introduction of PMA treatment for the exclusive detection of living bacteria is an important tool to overcome the detection of DNA from dead cells, a striking disadvantage of molecular methods. The results of the present study stress the importance of effective bacterial cell lysis as a crucial step toward the almost complete detection of the living bacterial community present in raw milk. Although it was shown that the phylum Firmicutes is strongly discriminated by the lysis approaches used, the importance of cultureindependent methods was emphasized. As can be seen in Tables 1 and 2, different species of the same genus were detected by the respective methods. The genera Aeromonas and Ralstonia as well as the genus Sphingobacterium were only detected in the clone libraries of samples M2 and M3, respectively. With the endpoint PCR method used in the present study, no quantitative statements about bacterial community composition of the bulk tank raw milk samples could be made. After achievement of more effective cell lysis and direct DNA extraction, fast quantitative molecular methods could be developed to capture the bacterial community structure in raw milk almost completely.

The results of the present study lead to the conclusion that the combination of culture-dependent and -independent methods is the best choice to cover the bacterial community composition of bulk tank raw milk. This result is in accordance with the conclusions of Delbès et al. (2007) and Fricker et al. (2011). In our study, PMA treatment was successfully introduced for the milk matrix and was found to be applicable in this matrix for direct detection of viable cells. This could help to focus direct methods for those populations that may represent a risk for product quality and safety.

\section{ACKNOWLEDGMENTS}

This research was conducted in the Center of Integrated Dairy Research (CIDRe), University of Bonn (Bonn, Germany).

\section{REFERENCES}

Altschul, S. F., W. Gish, W. Miller, E. W. Myer, and D. J. Lipman. 1990. Basic local alignment search tool. J. Mol. Biol. 215:403-410.

Ashelford, K. E., N. A. Chuzhanova, J. C. Fry, A. J. Jones, and A. J. Weightman. 2005. At least 1 in $2016 \mathrm{~S}$ rRNA sequence records currently held in public repositories is estimated to contain substantial anomalies. Appl. Environ. Microbiol. 71:7724-7736.

Bae, S., and S. Wuertz. 2009. Discrimination of viable and dead fecal Bacteroidales bacteria by quantitative PCR with propidium monoazide. Appl. Environ. Microbiol. 75:2940-2944.

Cattani, F., C. A. S. Ferreira, and S. D. Oliveira. 2013. The detection of viable vegetative cells of Bacillus sporothermodurans using propidium monoazide with semi-nested PCR. Food Microbiol. 34:196-201.

Cawthorn, D.-M., and R. C. Witthuhn. 2008. Selective PCR detection of viable Enterobacter sakazakii cells utilizing propidium monoazide or ethidium bromide monoazide. J. Appl. Microbiol. 105:1178-1185.

Cremonesi, P., B. Castiglioni, G. Malferrari, I. Biunno, C. Vimercati, P. Moroni, S. Morandi, and M. Luzzana. 2006. Technical note: Improved method for rapid DNA extraction of mastitis pathogens directly from milk. J. Dairy Sci. 89:163-169.

Delbès, C., L. Ali-Mandjee, and M.-C. Montel. 2007. Monitoring bacterial communities in raw milk and cheese by culture-dependent and -independent 16S rRNA gene-based analyses. Appl. Environ. Microbiol. 73:1882-1891.

Desfossés-Foucault, É., V. Dussault-Lepage, C. Le Boucher, P. Savard, G. LaPointe, and D. Roy. 2012. Assessment of probiotic viability during Cheddar cheese manufacture and ripening using propidium monoazide-PCR quantification. Front. Microbiol. 3:350.

Di Pinto, A., V. T. Forte, M. C. Guastadisegni, C. Martino, F. P. Schena, and G. Tantillo. 2007. A comparison of DNA extraction methods for food analysis. Food Contr. 18:76-80.

Fittipaldi, M., A. Nocker, and F. Codony. 2012. Progress in understanding preferential detection of live cells using viability dyes in combination with DNA amplification. J. Microbiol. Methods 91:276-289.

Fricker, M., B. Skånseng, K. Rudi, B. Stessl, and M. Ehling-Schulz. 2011. Shift from farm to dairy tank milk microbiota revealed by a polyphasic approach is independent from geographical origin. Int. J. Food Microbiol. 145:S24-S30.

García-Cayuela, T., R. Tabasco, C. Pelaéz, and T. Requena. 2009. Simultaneous detection and enumeration of viable lactic acid bacteria and bifidobacteria in fermented milk by using propidium monoazide and real-time PCR. Int. Dairy J. 19:405-409.

Gerhardt, P., R. G. E. Murray, R. N. Costilow, E. W. Nester, W. A. Wood, N. R. Krieg, and G. Briggs Phillips, editors. 1981. Manual of Methods for General Bacteriology. American Society for Microbiology, Washington, DC

Giraffa, G., and E. Neviani. 2001. DNA-based, culture-independent strategies for evaluating microbial communities in food-associated ecosystems. Int. J. Food Microbiol. 67:19-34. 
Good, I. J. 1953. The population frequencies of species and the estimation of population parameters. Biometrika 40:237-264.

Hantsis-Zacharov, E., and M. Halpern. 2007. Culturable psychrotrophic bacterial communities in raw milk and their proteolytic and lipolytic traits. Appl. Environ. Microbiol. 73:7162-7168.

Hayes, M. C., R. D. Ralyea, S. C. Murphy, N. R. Carey, J. M. Scarlett, and K. J. Boor. 2001. Identification and characterization of elevated microbial counts in bulk tank raw milk. J. Dairy Sci 84:292-298.

Josephson, K. L., C. P. Gerba, and I. L. Pepper. 1993. Polymerase chain reaction detection of nonviable bacterial pathogens. Appl. Environ. Microbiol. 59:3513-3515.

Justé, A., B. P. H. J. Thomma, and B. Lievens. 2008. Recent advances in molecular techniques to study microbial communities in foodassociated matrices and processes. Food Microbiol. 25:745-761.

Kim, O.-S., Y.-J. Cho, K. Lee, S.-H. Yoon, M. Kim, H. Na, S.-C. Park, Y. S. Jeon, J.-H. Lee, H. Yi, S. Won, and J. Chun. 2012. Introducing EzTaxon-e: A prokaryotic 16S rRNA gene sequence database with phylotypes that represent uncultured species. Int. J. Syst. Evol. Microbiol. 62:716-721.

Lafarge, V., J.-C. Ogier, V. Girard, V. Maladen, J.-Y. Leveau, A Gruss, and A. Delacroix-Buchet. 2004. Raw cow milk bacterial population shifts attributable to refrigeration. Appl. Environ. Microbiol. 70:5644-5650.

Lebaron, P., J.-F. Ghiglione, C. Fajon, N. Batailler, and P. Normand 1998. Phenotypic and genetic diversity within a colony morphotype. FEMS Microbiol. Lett. 160:137-143.

Lipski, A., and K. Altendorf. 1997. Identification of heterotrophic bacteria isolated from ammonia-supplied experimental biofilters. Syst. Appl. Microbiol. 20:448-457.

McKillip, J. L., L.-A. Jaykus, and M. Drake. 1999. Nucleic acid persistence in heat-killed Escherichia coli O157:H7 from contaminated skim milk. J. Food Prot. 62:839-844.

Messing, J. 1983. New M13 vectors for cloning. Methods Enzymol. 101:20-78

Muyzer, G., A. Teske, C. O. Wirsen, and H. W. Jannasch. 1995. Phylogenetic relationships of Thiomicrospira species and their identification in deep-sea hydrothermal vent samples by denaturing gradient gel electrophoresis of $16 \mathrm{~S}$ rDNA fragments. Arch. Microbiol. 164:165-172

Nichols, P. D., J. B. Guckert, and D. C. White. 1986. Determination of monounsaturated fatty acid double-bond position and geometry for microbial monocultures and complex consortia by capillary GC-MS of their dimethyl disulphide adducts. J. Microbiol. Methods 5:49-55.

Nocker, A., C.-Y. Cheung, and A. K. Camper. 2006. Comparison of propidium monoazide with ethidium monoazide for differentiation of live vs. dead bacteria by selective removal of DNA from dead cells. J. Microbiol. Methods 67:310-320.

Nocker, A., A. Mazza, L. Masson, A. K. Camper, and R. Brousseau. 2009. Selective detection of live bacteria combining propidium monoazide sample treatment with microarray technology. J. Microbiol. Methods 76:253-261

Nogva, H. K., S. M. Drømtorp, H. Nissen, and K. Rudi. 2003. Ethidium monoazide for DNA-based differentiation of viable and dead bacteria by 5 '-nuclease PCR. Biotechniques 34:804-808,810,812813.

Oliver, J. D. 2005. The viable but nonculturable state in bacteria. J. Microbiol. 43:93-100.

Pantoja, J. C. F., D. J. Reinemann, and P. L. Ruegg. 2011. Factors associated with coliform count in unpasteurized bulk milk. J. Dairy Sci. 94:2680-2691.

Quigley, L., R. McCarthy, O. O'Sullivan, T. P. Beresford, G. F. Fitzgerald, R. P. Ross, C. Stanton, and P. D. Cotter. 2013. The microbial content of raw and pasteurized cow milk as determined by molecular approaches. J. Dairy Sci. 96:4928-4937.
Raats, D., M. Offek, D. Minz, and M. Halpern. 2011. Molecular analysis of bacterial communities in raw cow milk and the impact of refrigeration on its structure and dynamics. Food Microbiol. 28:465-471.

Rasolofo, E. A., D. St-Gelais, G. LaPointe, and D. Roy. 2010. Molecular analysis of bacterial population structure and dynamics during cold storage of untreated and treated milk. Int. J. Food Microbiol. 138:108-118.

Saitou, N., and M. Nei. 1987. The neighbor-joining method: A new method for reconstructing phylogenetic trees. Mol. Biol. Evol. $4: 406-425$.

Sasser, M. 1990. Identification of bacteria through fatty acid analysis. Pages 199-204 in Methods in Phytobacteriology. Z. Klement, K. Rudolph, and D. C. Sands, ed. Akadémiai Kiadó, Budapest, Hungary.

Shannon, C. E., and W. Weaver. 1969. The Mathematical Theory of Communication. 4th print of the paperback ed. The Univ. of Illinois Press, Urbana.

Singleton, D. R., M. A. Furlong, S. L. Rathbun, and W. B. Whitman. 2001. Quantitative comparisons of $16 \mathrm{~S}$ rRNA gene sequence libraries from environmental samples. Appl. Environ. Microbiol. $67: 4374-4376$

Soejima, T., J. Minami, and K. Iwatsuki. 2012. Rapid propidium monoazide PCR assay for the exclusive detection of viable Enterobacteriaceae cells in pasteurized milk. J. Dairy Sci. 95:3634-3642.

Suzuki, M. T., and S. J. Giovannoni. 1996. Bias caused by template annealing in the amplification of mixtures of $16 \mathrm{~S}$ rRNA genes by PCR. Appl. Environ. Microbiol. 62:625-630.

Tamura, K., D. Peterson, N. Peterson, G. Stecher, M. Nei, and S. Kumar. 2011. MEGA5: Molecular evolutionary genetics analysis using maximum likelihood, evolutionary distance, and maximum parsimony methods. Mol. Biol. Evol. 28:2731-2739.

Teh, K. H., S. Flint, J. Palmer, D. Lindsay, P. Andrewes, and P. Bremer. 2011. Thermo-resistant enzyme-producing bacteria isolated from the internal surfaces of raw milk tankers. Int. Dairy J. 21:742-747.

Thompson, J. D., D. G. Higgins, and T. J. Gibson. 1994. CLUSTAL $\mathrm{W}$ : Improving the sensitivity of progressive multiple sequence alignment through sequence weighting, position-specific gap penalties and weight matrix choice. Nucleic Acids Res. 22:4673-4680.

Vacheyrou, M., A.-C. Normand, P. Guyot, C. Cassagne, R. Piarroux, and Y. Bouton. 2011. Cultivable microbial communities in raw cow milk and potential transfers from stables of sixteen French farms. Int. J. Food Microbiol. 146:253-262.

Verdier-Metz, I., G. Gagne, S. Bornes, F. Monsallier, P. Veisseire, C. Delbès-Paus, and M.-C. Montel. 2012. Cow teat skin, a potential source of diverse microbial populations for cheese production. Appl. Environ. Microbiol. 78:326-333.

Verdier-Metz, I., V. Michel, C. Delbès, and M.-C. Montel. 2009. Do milking practices influence the bacterial diversity of raw milk? Food Microbiol. 26:305-310.

von Wintzingerode, F., U. B. Göbel, and E. Stackebrandt. 1997. Determination of microbial diversity in environmental samples: Pitfalls of PCR-based rRNA analysis. FEMS Microbiol. Rev. 21:213-229.

Wiertz, R., S. C. Schulz, U. Müller, P. Kämpfer, and A. Lipski. 2013. Corynebacterium frankenforstense sp. nov. and Corynebacterium lactis sp. nov., isolated from raw cow milk. Int. J. Syst. Evol. Microbiol. 63:4495-4501.

Wilson, I. G. 1997. Inhibition and facilitation of nucleic acid amplification. Appl. Environ. Microbiol. 63:3741-3751.

Yeung, M. 2012. ADSA Foundation Scholar Award: Trends in cultureindependent methods for assessing dairy food quality and safety: Emerging metagenomic tools. J. Dairy Sci. 95:6831-6842.

Yuan, S., D. B. Cohen, J. Ravel, Z. Abdo, and L. J. Forney. 2012. Evaluation of methods for the extraction and purification of DNA from the human microbiome. PLoS ONE 7:e33865. 


\section{APPENDIX}

Table A1. Fatty acid profiles of the isolate groups 1 to 5 (with SD in parentheses) and the number of isolates for each group, cell morphology, and Gram-staining results

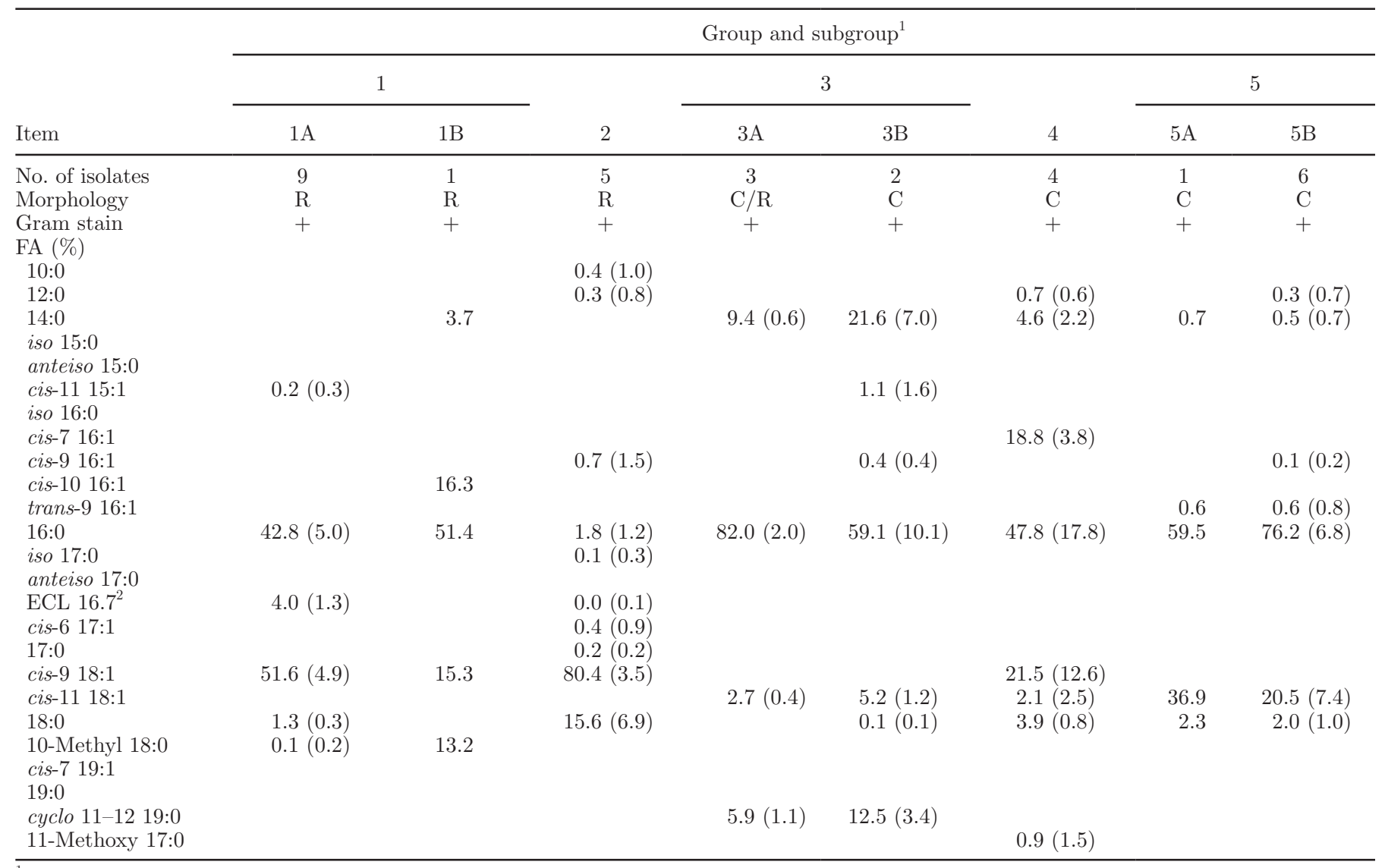

${ }^{1} \mathrm{R}=$ rod shaped; $\mathrm{C}=$ coccoid + = gram positive.

${ }^{2} \mathrm{ECL}=$ equivalent chain length. 
Table A2. Fatty acid profiles of the isolate groups 6 to 10 (with SD in parentheses) and the number of isolates for each group, cell morphology, and Gram-staining results

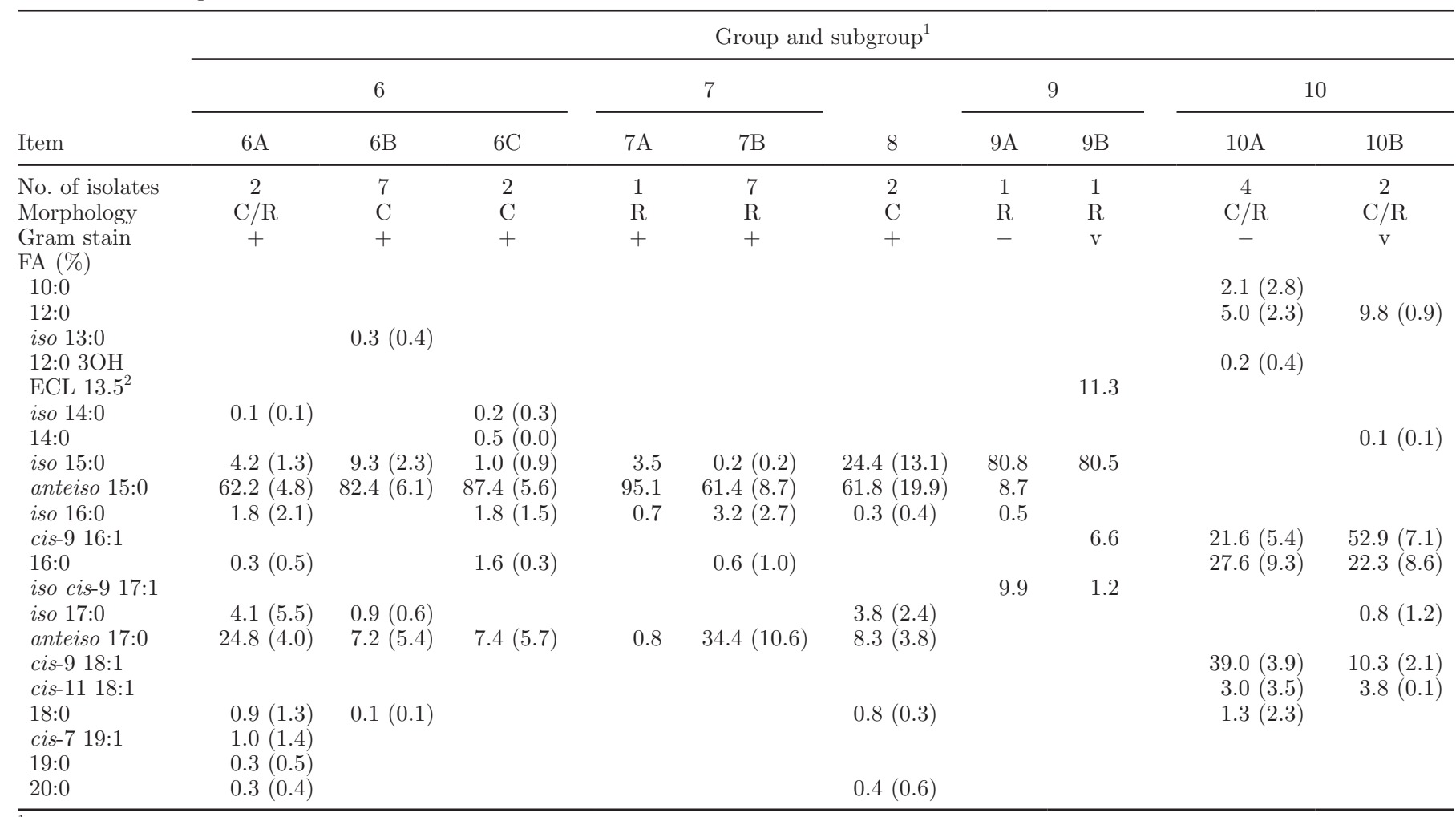

${ }^{1} \mathrm{R}=$ rod shaped $\mathrm{C}=$ coccoid $;+=$ gram positive $-=$ gram negative; $\mathrm{v}=$ gram variable.

${ }^{2} \mathrm{ECL}=$ equivalent chain length. 
Table A3. Fatty acid profiles of the isolate groups 11 to 17 (with SD in parentheses) and the number of isolates for each group, cell morphology, and Gram-staining results

\begin{tabular}{|c|c|c|c|c|c|c|c|c|c|}
\hline \multirow[b]{3}{*}{ Item } & \multicolumn{9}{|c|}{ Group and subgroup ${ }^{1}$} \\
\hline & \multirow[b]{2}{*}{11} & \multirow[b]{2}{*}{12} & \multirow[b]{2}{*}{13} & \multicolumn{3}{|c|}{14} & \multirow[b]{2}{*}{15} & \multirow[b]{2}{*}{16} & \multirow[b]{2}{*}{17} \\
\hline & & & & $14 \mathrm{~A}$ & $14 \mathrm{~B}$ & $14 \mathrm{C}$ & & & \\
\hline No. of isolates & 1 & 1 & 1 & 1 & 1 & 1 & 12 & 2 & 13 \\
\hline Morphology & $\mathrm{C}$ & $\mathrm{R}$ & $\mathrm{R}$ & $\mathrm{C}$ & $\mathrm{R}$ & $\mathrm{R}$ & $\mathrm{C}$ & $\mathrm{C}$ & $\mathrm{R}$ \\
\hline Gram stain & + & $\mathrm{v}$ & + & + & $\mathrm{v}$ & + & $+/ \mathrm{v}$ & + & $-/ \mathrm{v}$ \\
\hline $\begin{array}{l}\text { FA }(\%) \\
10: 0\end{array}$ & & & & & & & & & $0.1(0.1)$ \\
\hline $12: 0$ & 2.3 & & & & & & & & $5.8(0.9)$ \\
\hline iso $13: 0$ & & & & & & & $0.1(0.2)$ & & \\
\hline $12: 03 \mathrm{OH}$ & & & & & & & & & $0.4(0.2)$ \\
\hline $\begin{array}{l}\text { iso } 14: 0 \\
14: 0\end{array}$ & 3.8 & 0.8 & & & & & & $0.4(0.1)$ & \\
\hline iso $15: 0$ & & & & 1.0 & 3.2 & 6.8 & $3.3(0.8)$ & $0.1(0.1)$ & \\
\hline anteiso $15: 0$ & & & & 75.6 & 72.6 & 77.0 & $92.5(2.1)$ & $91.6(1.6)$ & \\
\hline $15: 0$ & & 0.6 & & & & & & & \\
\hline $14: 02 \mathrm{OH}$ & & 3.0 & & & & & & & \\
\hline iso 16:0 & & & & & 10.2 & & & $6.0(1.4)$ & \\
\hline $\begin{array}{l}\text { cis-9 } 16: 1 \\
\text { cis-11 } 16: 1\end{array}$ & 26.5 & $\begin{array}{r}28.3 \\
1.2\end{array}$ & 0.4 & & & & & & $8.6(3.0)$ \\
\hline $16: 0$ & 57.8 & 20.0 & 5.9 & & & & $0.1(0.4)$ & & $44.3(3.0)$ \\
\hline iso $17: 0$ & & & & 1.3 & 0.5 & 4.1 & $0.5(0.3)$ & & \\
\hline anteiso $17: 0$ & & & & 19.3 & 13.5 & 12.0 & $3.4(1.6)$ & $1.9(0.0)$ & \\
\hline cis-11 17:1 & & 2.5 & & & & & & & \\
\hline cyclo 17:0 & 6.2 & & & & & & & & \\
\hline $17: 0$ & & & 0.7 & & & & & & \\
\hline cis-9 $18: 1$ & & & & & & & & & $40.3(3.5)$ \\
\hline $\begin{array}{l}\text { cis-11 18:1 } \\
18 \cdot 0\end{array}$ & 3.4 & 41.8 & $\begin{array}{r}57.2 \\
6.8\end{array}$ & 0.9 & & & $0.2(0.3)$ & & \\
\hline $\begin{array}{l}\text { 18:0 } \\
\text { cis-11 11-methyl 18:1 }\end{array}$ & & 0.3 & $\begin{array}{l}6.8 \\
0.5\end{array}$ & 0.9 & & & $0.2(0.3)$ & & $0.5(0.6)$ \\
\hline $\begin{array}{l}\text { cls-11 11-methyl 18:1 } \\
\text { iso 19:0 }\end{array}$ & & 1.0 & & 0.3 & & & & & \\
\hline anteiso 19:0 & & & & 1.4 & & & & & \\
\hline cyclo 11-12 19:0 & & & 28.4 & & & & & & \\
\hline $20: 0$ & & & & 0.2 & & & & & \\
\hline
\end{tabular}

${ }^{1} \mathrm{R}=$ rod shaped $\mathrm{C}=$ coccoid $;+=$ gram positive $;-=$ gram negative; $\mathrm{v}=$ gram variable. 
WEBER ET AL.

Table A4. Fatty acid profiles of the isolate groups 18 to 22 (with SD in parentheses) and the number of isolates for each group, cell morphology, and Gram-staining results

\begin{tabular}{|c|c|c|c|c|c|c|c|}
\hline \multirow[b]{3}{*}{ Item } & \multicolumn{7}{|c|}{ Group and subgroup ${ }^{1}$} \\
\hline & \multirow[b]{2}{*}{18} & \multicolumn{2}{|c|}{19} & \multirow[b]{2}{*}{20} & \multicolumn{2}{|c|}{21} & \multirow[b]{2}{*}{22} \\
\hline & & $19 \mathrm{~A}$ & 19B & & $21 \mathrm{~A}$ & $21 \mathrm{~B}$ & \\
\hline No. of isolates & 7 & 14 & 1 & 1 & 1 & 1 & 1 \\
\hline Morphology & $\mathrm{R}$ & $\mathrm{R}$ & $\mathrm{R}$ & $\mathrm{C}$ & $\mathrm{R}$ & $\mathrm{R}$ & $\mathrm{R}$ \\
\hline Gram stain & - & $-/ \mathrm{v}$ & - & + & - & - & - \\
\hline \multicolumn{8}{|l|}{ FA $(\%)$} \\
\hline ECL $10.85^{2}$ & & $3.6(1.3)$ & 2.9 & & & & \\
\hline 10:0 $3 \mathrm{OH}$ & $0.1(0.1)$ & & & & & & \\
\hline $12: 0$ & $1.6(0.2)$ & $2.4(0.2)$ & 0.8 & & & & \\
\hline iso 13:0 & & & & & & 0.5 & \\
\hline $12: 02 \mathrm{OH}$ & $0.2(0.1)$ & & & & & & \\
\hline $12: 03 \mathrm{OH}$ & $0.2(0.2)$ & & & & & & \\
\hline ECL 13.5 & & & & & 9.0 & 9.5 & \\
\hline $14: 0$ & & $2.2(0.2)$ & 1.9 & & & & 0.7 \\
\hline iso 15:0 & & & & & 53.1 & 83.6 & 49.4 \\
\hline anteiso 15:0 & & & & & 8.8 & & 0.7 \\
\hline $15: 0$ & & $0.2(0.1)$ & 0.7 & & & & \\
\hline $14: 03 \mathrm{OH}$ & & $0.3(0.2)$ & 0.2 & & & & \\
\hline iso $16: 0$ & & & & & 0.1 & & \\
\hline cis-9 $16: 1$ & $24.0(3.2)$ & $9.1(2.0)$ & 42.6 & & & & 39.6 \\
\hline iso $15: 02 \mathrm{OH}$ & & & & & 1.9 & 0.7 & \\
\hline $16: 0$ & $66.9(4.3)$ & $56.9(4.1)$ & 42.2 & 8.8 & 0.3 & 0.1 & 8.5 \\
\hline iso $15: 03 \mathrm{OH}$ & & & & & 0.1 & 0.1 & 0.4 \\
\hline iso cis-9 $17: 1$ & & & & & 24.5 & 4.9 & \\
\hline iso $17: 0$ & & & & & 0.7 & & \\
\hline ECL 16.7 & & & & 64.4 & & & \\
\hline cyclo $17: 0$ & $2.3(1.4)$ & $4.1(1.6)$ & 0.1 & & & & \\
\hline $17: 0$ & & $0.1(0.1)$ & 0.5 & & & & \\
\hline 16:0 $3 \mathrm{OH}$ & & & & & & & 0.3 \\
\hline cis-9 18:1 & & & & 26.2 & & & \\
\hline cis-11 18:1 & $4.5(1.0)$ & $21.0(2.8)$ & 8.1 & & & & \\
\hline $18: 0$ & $0.0(0.1)$ & & & 0.6 & & & \\
\hline iso $17: 0 \mathrm{3OH}$ & & & & & 1.4 & 0.6 & 0.5 \\
\hline
\end{tabular}

${ }^{1} \mathrm{R}=$ rod shaped; $\mathrm{C}=$ coccoid $;+=$ gram-positive; $-=$ gram negative; $\mathrm{v}=$ gram variable.

${ }^{2} \mathrm{ECL}=$ equivalent chain length. 